\title{
Ascertaining the UX of the Word Mania Mobile App for Children using Fun Toolkit v3
}

\author{
Azham Hussain, Emmanuel O.C. Mkpojiogu, Fazillah Mohmad Kamal, Huda Mohammed \\ Lateef
}

\begin{abstract}
A user experience evaluation was carried on Word Mania mobile app. Word Mania is fun educational games app for children. Fun Tookit v3, a survey instrument developed to assist researchers in acquiring the opinions about technology (web or app) from children was used for data capture. The purpose of the toolkit is to generate the perception of kids as young as 4 years old who had some experience when interacting with an implementation. The Fun Toolkit v3 tool consists of three components that can be used on applications, websites or technology products to "pass opinions." These three sections are: Smileyometer, Fun Sorter, Again and Again.At UUM International School, Sintok, Malaysia, this assessment study was performed with students. The survey was attended by a total of 12 students. The evaluation questionnaires were filled out with the help of their teachers by the participating children.The findings stated that the mobile application was adopted by the kids; however, some problems had to pay attention in order to enhance the children's user experience.Special exercises should be found for children aged one or two years because current exercises are difficult for these ages. Competition task is not an simple task, particularly for kids aged 3 to 4 years. Children between the ages of 5 and 6 need more time to complete the tasks, for these ages three minutes are not enough.
\end{abstract}

Keywords: Children, fun education, games experience, mobile app, user experience evaluation

\section{INTRODUCTION}

In today's contemporary societies, it is evident that electronic games (EG) have key role to play especially in the lives of young ones. However, EG is known to have a major impact in the society, culturally and economically.It particularly impacts on young people. However, theside effects among young ones include the reasonable amount of time they invest on the electronic games. It can be assumed that a child below the age of 10 years has access to computer systems and many other mobile accessories. It can be inferred that many of these children have been raised with access to computer games and can easily manipulate computer games with ease.

Revised Manuscript Received on June 22, 2019.

Azham Hussain, School of Computing, Universiti Utara Malaysia, 06010 UUM, Sintok, Malaysia

Emmanuel O.C. Mkpojiogu, Department of Computer and Information Technology, Veritas University, Abuja, Nigeria.

Fazillah Mohmad Kamal, School of Quantitative Sciences, Universiti Utara Malaysia, 06010 UUM, Sintok, Malaysia

Huda Mohammed Lateef, Faculty of Applied Science, University of Fallujah, Baghdad, Iraq.
The increase in electronic accessories market like computer games has intensified the need for researchers to focus on the cognitive abilities that formal studies could not provide taking the advantage of electronic games to proffer solutions to cognitive education and at same time providing entertainment for children. This will keep students motivated by generating personal interest in studying via a different approach (fun education). Children enjoy letters and video clips using mobile devices. Also, children exhibitpositive behavior and action from the video clips and letter they see in mobile devices. They get motivated watching and learning letters and video clips from mobile phones. Mobile learning improves literacy level among children. However, a there is huge difference among kids as a result of involvement in mobile learning. Nonetheless, children perceived use of these devices is heavily based on entertainment instead of on learning especially with regard to the download of games via online stores like android or Apple play store. Consequently, the addiction to mobile app among kids is a phenomenon that concerns both parents and educators. The increasing levelof apps on the internet is alarming. These contents of these apps may be inappropriate for kids which may not be educationally inclined. A much needed educational-based app will be a best-fit that will sincerely satisfy the gratification of learning and entertainment. A typical example is an App called WordMania. WordMania game is an interactive game. It has the goal ofletting children find as many words as possible from a given pairs of letters over a period of time. The game contains other boards that allow competition among other players.

When finding or selecting good educational apps for their kids, parents face different concerns and difficulties. "Parents are concerned about the educational quality, the age appropriateness of the app, and whether the privacy of their children is protected," according to Lee (2014).Meanwhile, McCoy (2013) states that "parents are concerned with the content of the app and the information collected when children use the app." Moreover, as of July 2014, parents are overwhelmed by the large number of apps available in Apple's App Store (1.2 million) and Google Play (1.3 million).This makes it challenging to find good educational applications for children (Harlen, 2018).One of the most critical years in his or her career to affect learning is the years before a kid reaches kindergarten. Early childhood is a vital period of time for developing children's mental functions.Nowadays kids are very advanced as they are exposed to the world with high technology. 
Consequently, parents or guardians cannot expect them to learn using the traditional ways as to how the previous generation used to learn. So, in this case, a special learning system which could be interactive and fun and which also provide convenience and mobility to the user should be a good option for children. Early childhood learning is important for the development of children's abilities and skills in fields such as language, motor skills, cognitive psychosocial and learning. This is now known to be heavily affected exogenous factors, including the nature of the educational environment the kid is subjected to during the first four to eight years of life (Geist \&Hohn, 2009). The other problems are stated in cases where: 1) Children not attracted with traditional studies (books); 2) Children easily lose focus during the study: 3) Need parents or teachers to accompany them; 4) Lastly, most of the software that is related with education in the market tends more toward the English language. It is known that, not all children can understand and comprehend English language (Prensky, 2006).

Word Mania is an interactive online word-building game in which players are given 15 letters randomly chosen within 3 minutes to generate as many phrases as possible. Any right word produced by players earns them points.Consequently, longer and more complex words gives better points and using specials letter tiles (Gold and Diamond). Various literacy skills like morphemes, word recognition, spelling, vocabulary, phonemes, word knowledge, affixes and plural are required when words are built. Word Mania is one of the thousands of fun and educational exercises LiteracyPlanet has created. LiteracyPlanet is the premier resource for children in online literacy education. Word Mania's most important rule is having fun.The other is for students to play their games without help. Students must be logged in and play without assistance to contribute valid competition scores. By logging out and using the practice game, students can practice with parents or helpers. WordMania challenge can be adopted in Malaysia to demonstrate how technology can be employed for learning among children as well as engaging their minds.

The main objective of this study is to evaluate the Word Mania app for children aged 4 to 9 years old. Most people like to play games including children. This study takes this opportunity in order to attract children around aged 4 to 9 years to play the game app and at the same time learn some basic stuff. Therefore, the purpose of the study is to find out user experience of children using the Word Mania mobile app.The study targets at: 1) the education of children who are aged 4 to 9 years; 2 ) it focuses on how children can form as many letters as possible within three minutes and identify objects based on the alphabet in English by assuming that children know the basic way of interacting with mobile device.; 3) Improving the vocabulary spelling. In the study, 12 students at UUM International School were given a survey questionnaire to be finished with minimal help from the teachers of the children. Participants also need to have prior experience using smart devices like a smartphone or tablet.

\section{METHODOLOGY}

Fun Tookit v3 is a survey instrument used to assist researchers in acquiring the opinions of children about technology (web or app) (Read, 2008). It was originally developed by Read as a notion in 2000 before going through a sequence of iterations and reviews. The Fun ToolKit was later described in Read and McFarlane (2006) as a consequence of these reviews.Fun Toolkit has therefore demonstrated to be very helpful in collecting opinions from kids with a significantly acceptable degree of trust. The toolkit is intended to provide fun, quick and honest experience for kids as young as 4 years of age when engaging with an application.The Fun Toolkit v3 instruments include:Smileyometer, Fun Sorter, Again and Again tables. This instrument was used in this study to capture the user experience (UX) of the Word Mania mobile app (For more on UX see: Hussain et al., 2016a; 2016b, 2017a; 2017b; 2018). The study was conducted with pupils at the UUM International School, Sintok, Malaysia. The study was attended by a total of 12 students. The tasks for the study were developed. With the help of their teachers, the participating kids filled out the questionnaires. The following threetaskswere performed by the children on this App on mobile phone: 1) find out the letters of the alphabets; 2)abilityto challenge;and 3) write the correct word.

Smileyo meter: The Fun Toolkit smileyometer was used to measure the children's fun experience in terms of how fun it was to use the App's different activities. Figure 1 demonstrates a five-point scale (Awful, Not very good, Good, Really nice, Brilliant) used to record the children's reaction to the tasks (e.g. Task 2) as well as the general App.

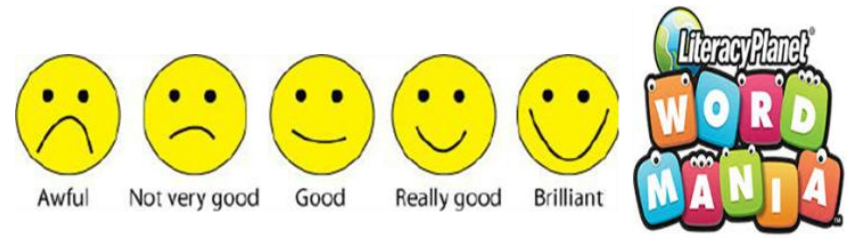

Fig. 1 a five-point scale

Fun-Sorter: Fun-Sorter was utilized to sort fun experienced while carrying out the tasks. As indicated by the participants, Task 1 was the most effortless undertaking to do. They discovered Task 2 as the most pleasant action when contrasted with two different exercises. See Table 1.

Table. 1 Fun Sorter Table

\begin{tabular}{|l|l|l|l|}
\hline & Best & & Worst \\
\hline $\begin{array}{l}\text { Easiest to } \\
\text { do }\end{array}$ & & & \\
\hline Most Fun & & & \\
\hline
\end{tabular}

Again-Again: Again-Again table was used to ask the children's opinion whether or not they would like to use the App to do the exercise (task) again to capture an impression of engagement, as shown in Table 2. 
Table. 2 Again-Again Table

\begin{tabular}{|l|l|l|l|l|}
\hline \multicolumn{6}{|l|}{ Would you like to use Word Mania Application Again } \\
\hline Child name & Child age & Yes & Maybe & No \\
\hline & & & & \\
\hline & & & & \\
\hline
\end{tabular}

\section{RESULTS}

The information for this study was analyzed using SPSS v 23. Of the 12 participating kids, $58 \%$ were boys and $42 \%$ were females. $48 \%$ ranged between $4-5$ years of age and $16 \%$ ranged between 6-7 years of age and $36 \%$ ranged between 8-9 years of age.Each of the 12 kids finished the smileyometer before and after each of the three tasks was performed and the outcomes are shown in Table 3.

Table. 3 Mean scores and standard Deviation for Smileyometer

\begin{tabular}{|l|l|l|l|l|}
\hline & \multicolumn{3}{l|}{ Before } & \multicolumn{2}{l|}{ After } \\
\hline & Mean & SD & Mean & SD \\
\hline Task1 & 4.08 & 1.37 & 3.33 & 1.49 \\
\hline Task2 & 3.66 & .88 & 2.83 & 1.33 \\
\hline Task3 & 4.25 & 1.21 & 3.25 & 1.42 \\
\hline
\end{tabular}

For task 1, 2, and 3, the results of the Smileyometer before and after revealed that the expectations of the kids had not been met. The participants were asked to report on each of the tasks (activity) using Smileyometer: "How much fun was using the app?" Figure 2 demonstrates the participants ' Smileyometer responses.For the task 1, "Brilliant" was $33.33 \%$ of the participants ' reaction and "Really Good" was the reaction of $16.67 \%$ of participants. $8.33 \%$ of the participants rated "Brilliant" and "Really Good" rated 33\% for Task 2.However, in the task 3, 41.67\% of the participants responded as "Really Good" and $16.67 \%$ rated as Brilliant. According to the Smileyometer results, the maximum positive response was reported for task 1 .
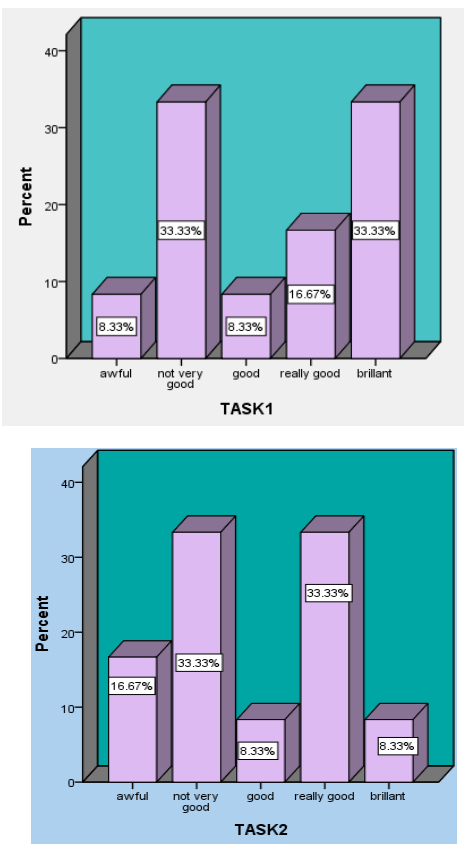

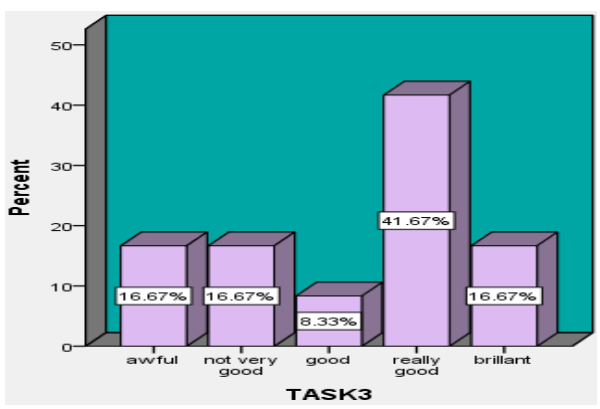

Fig. 2 Smileyometer results for each task

Another evaluation technique was carried out using the Again-Again table where participants were asked to report on each assignment: "Do you want to use this app again?" Reporting the outcomes in Table 4 below.

Table . 4 Frequency response in whether participants would like to repeat play activity again

\begin{tabular}{|l|l|l|l|}
\hline & Yes & Maybe & No \\
\hline Task1 & 4 & 2 & 6 \\
\hline Task2 & 6 & 3 & 3 \\
\hline Task3 & 8 & 1 & 3 \\
\hline
\end{tabular}

It is clear from the results that most children had more preference for task 2 and task 3. Most kid indicated that they would not like to do task 1 again. The third evaluation "The Fun Sorter" looked at two most fun and easy-to-play constructs and showed the outcomes in Table 5.

Table .5 Number of children who selected a preference for task based on the two constructs.

\begin{tabular}{|l|l|l|l|}
\hline & Task1 & Task2 & Task3 \\
\hline Most Fun & 10 & 6 & 2 \\
\hline $\begin{array}{l}\text { Easiest to } \\
\text { play }\end{array}$ & 9 & 4 & 6 \\
\hline
\end{tabular}

The Fun Sorter recognized a preference for task 1 in line with the other outcomes reported for the Fun Toolkit than for other two tasks. The mean scores were calculated with a peak value of 2 and a minimum of 1 depending on the combined outcomes of task1 in the Fun Toolkit.For task 1, the mean score was $1.67(\mathrm{SD}=.49)$. The combined tools score within the Fun Toolkit of task 2 and 3 shows a maximum value of 2 and a minimum value of 1 . The mean score was $1.67(\mathrm{SD}=.49)$. The final analysis looked at which task was preferred by each child, the results are presented in table 6 , where $\mathrm{T} 1=$ Task1, T2=Task 2 and T3 = Task3 . 
Table. 6 Task which came out on top in each of the evaluation instrument.

\begin{tabular}{|l|l|l|l|l|l|}
\hline & $\begin{array}{l}\text { Child } \\
\text { age }\end{array}$ & SSmiley & FS1Fun & FS2Ease & AA \\
\hline $\begin{array}{l}\text { Child } \\
\mathbf{1}\end{array}$ & 3 & $\mathrm{~T} 1$ & $\mathrm{~T} 1$ & $\mathrm{~T} 1$ & $\mathrm{~T} 1$ \\
\hline $\begin{array}{l}\text { Child } \\
\mathbf{2}\end{array}$ & 3 & $\mathrm{~T} 1$ & $\mathrm{~T} 1$ & $\mathrm{~T} 1$ & $\mathrm{~T} 1$ \\
\hline $\begin{array}{l}\text { Child } \\
\mathbf{3}\end{array}$ & 4 & $\mathrm{~T} 1$ & $\mathrm{~T} 1$ & $\mathrm{~T} 1$ & $\mathrm{~T} 1$ \\
\hline $\begin{array}{l}\text { Child } \\
\mathbf{4}\end{array}$ & 4 & $\mathrm{~T} 1$ & $\mathrm{~T} 1$ & $\mathrm{~T} 1$ & $\mathrm{~T} 1$ \\
\hline $\begin{array}{l}\text { Child } \\
\mathbf{5}\end{array}$ & 5 & $\mathrm{~T} 2, \mathrm{~T} 3$ & $\mathrm{~T} 2$ & $\mathrm{~T} 2$ & $\mathrm{~T} 2$ \\
\hline $\begin{array}{l}\text { Child } \\
\mathbf{6}\end{array}$ & 5 & $\mathrm{~T} 2, \mathrm{~T} 3$ & $\mathrm{~T} 2$ & $\mathrm{~T} 3$ & $\mathrm{~T} 2$ \\
\hline $\begin{array}{l}\text { Child } \\
\mathbf{7}\end{array}$ & 6 & $\mathrm{~T} 2, \mathrm{~T} 3$ & $\mathrm{~T} 2$ & $\mathrm{~T} 2$ & $\mathrm{~T} 3$ \\
\hline $\begin{array}{l}\text { Child } \\
\mathbf{8}\end{array}$ & 7 & $\mathrm{~T} 3$ & $\mathrm{~T} 3$ & $\mathrm{~T} 3$ & $\mathrm{~T} 3$ \\
\hline $\begin{array}{l}\text { Child } \\
\mathbf{9}\end{array}$ & 8 & $\mathrm{~T} 2, \mathrm{~T} 3$ & $\mathrm{~T} 3$ & $\mathrm{~T} 3$ & $\mathrm{~T} 3$ \\
\hline $\begin{array}{l}\text { Child } \\
\mathbf{1 0}\end{array}$ & 8 & $\mathrm{~T} 2$ & $\mathrm{~T} 3$ & $\mathrm{~T} 2$ & $\mathrm{~T} 2$ \\
\hline $\begin{array}{l}\text { Child } \\
\mathbf{1 1}\end{array}$ & 9 & $\mathrm{~T} 3$ & $\mathrm{~T} 3$ & $\mathrm{~T} 2$ & $\mathrm{~T} 2$ \\
\hline $\begin{array}{l}\text { Child } \\
\mathbf{1 2}\end{array}$ & 9 & $\mathrm{~T} 3$ & $\mathrm{~T} 3$ & $\mathrm{~T} 3$ & $\mathrm{~T} 3$ \\
\hline
\end{tabular}

\section{CONCLUSION AND RECOMMENDATION}

UX evaluation is occupying a central part of software development. This paper introduced the most widely used methods for conducting the UX of mobile applications among children. The study showed the following results: Task 1 in Smileyometer got the highest value at 3.33 while Task 2 got the lowest value that was 2.83. In the Again and Againinstrument, Task 3, got the largest number of pupils who wish to play Word Mania application many more times. Task 1got the lowest number of pupils who wish to play WordMania again. The number of pupils was only four. In the "Sorter Fun" method, there were two parts, the first part was the Most Fun and the second part was Easiest to do; where Task 1 had the largest number of pupils at Most Fun while task3 had the lowest number of kids in the second part (Easiest to do),Task 1 got the largest number while task 2 got the lowest number of pupils. The Word Mania app is one of the most popular applications used to develop the English language skills of children. However, there are some issues to pay attention to in the app. Special exercises should be found for children aged one or two years because current exercises are difficult for these ages. Competition task is not an simple task, particularly for kids aged 3 to 4 years. Children between the ages of 5 and 6 need more time to complete the tasks, for these ages three minutes are not enough.

\section{REFERENCES}

1. Geist, E., \& Hohn, J. (2009). Encouraging Creativity in the Face of Administrative Convenience: How Our Schools Discourage Divergent Thinking. Education, 130(1).

2. Harlen, W. (2018). The teaching of science in primary schools. David Fulton Publishers.

3. Hussain, A., Mkpojiogu, E.O.C., Fadzil,N.M., \& Hassan, N.M. (2017) The UX of amila pregnancy on mobile device. Proceedings of the $2^{\text {nd }}$ International Conference on Applied Science and Technology (ICAST'17), Kedah, Malaysia. AIP Conference Proceedings 1891 (1), 020061, http://doi.org/10.1063/1.5005394

4. Hashim, N.L., Adamu, R. (2017), Usability evaluation of mobile banking application interfaces, Journal

5. of Engineering and Applied Sciences, Volume 12, Issue 21, 2017, Pages 5490-5494

6. Hussain, A., Mkpojiogu, E.O.C., Jamalsse, A., \& Mohammed, R.A. (2018). Grab mobile app: a UX assessment on mobile devices. Journal of Advanced Research in Dynamical and Control Systems (JARDCS), 10 (SI), 1233-1238.

7. Hussain, A., Mkpojiogu, E.O.C., \& Nawi, M.N.M. (2017). Capturing customer satisfaction and dissatisfaction in software requirements elicitation for features in proposed software systems. Journal of Engineering and Applied Sciences (JEAS), 12(21), 5590-5597

8. Hussain, A., Mkpojiogu, E.O.C. \& Yusof, M.M (2016). Perceived usefulness, perceived ease of use, and perceived enjoyment as drivers for the user acceptance of interactive mobile maps. Proceedings of the $1^{\text {st }}$ International Conference on Applied Science and Technology (ICAST'16), Kedah, Malaysia. AIP Conf. Proc. 1761 (1). 020051, http://dx.doi.org/10.1063/1.4960891

9. Lee. M. (2014, December 9). Parents Ask: Why Is It So Hard to Find Good Apps?. Joan Ganz Cooney Center. Retrieved from http://joanganzcooneycenter.org/2014/12/09/parents-ask-why-is-it-sohard-to-find-good-apps/

10. McCoy, A. (2013). How to protect your kids' safety when choosing apps. Retrieved from

http://specialsections.suntimes.com/education/prek12/1 7266560555/how-to-protect-your-kids-safety-when-choosing-apps.html

11. Prensky, M. (2006). Don't bother me, Mom, I'm learning!: How computer and video games are preparing your kids for $21 \mathrm{st}$ century success and how you can help! Paragon house St. Paul, MN.

12. Read, J. C., \& MacFarlane, S. (2006). Using the fun toolkit and other survey methods to gather opinions in child computer interaction. In Proceedings of the 2006 conference on Interaction design and children (pp. 81- 88). ACM.

13. Statista Inc., 2014. Number of apps available in leading app stores 2014. Retrieved from

http://www.statista.com/statistics/276623/number-ofapps-available-inleading-app-stores/ 